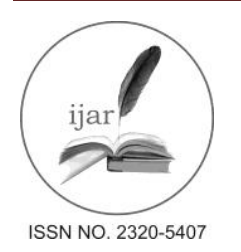

Journal homepage: http://www.journalijar.com
Journal DOI: 10.21474/IJAR01

INTERNATIONAL JOURNAL

RESEARCH ARTICLE

\title{
A COMPARATIVE STUDY OF ELECTROPHYSIOLOGICAL FINDINGS OF MOTOR NERVES IN PATIENTS WITH DIABETES MELLITUS AND HEALTHY CONTROLS IN AND AROUND DIBRUGARH TOWN.
}

\author{
*Risha Goswami ${ }^{1}$, Mamoni Dihingia ${ }^{1}$, Narayan Upadhyaya ${ }^{2}$, Snehankar Kalita ${ }^{3}$. \\ 1. Department of Physiology, Assam Medical College \& Hospital, Dibrugarh. \\ 2. Department of Neurology, Assam Medical College \& Hospital, Dibrugarh \\ 3. Department of Biochemistry, Assam Medical College \& Hospital, Dibrugarh
}

\section{Manuscript Info}

\section{Manuscript History:}

Received: 18 March 2016

Final Accepted: 19 April 2016

Published Online: May 2016

Key words:

Diabetes mellitus,

diabetic neuropathy,

motor nerves,

Electrophysiology,

nerve conduction

*Corresponding Author

Risha Goswami.

\begin{abstract}
Diabetes mellitus has emerged as a worldwide health problem with serious socioeconomic impacts. Vascular complications are predominant features of diabetes, owing to late presentation and delayed diagnosis. The most common and troublesome complication, associated with great mortality and morbidity is diabetic polyneuropathy which may be clinically evident or subclinical. Diabetic polyneuropathy begins early in course of diabetes, worsens gradually and becomes clinically evident when the condition is fairly advanced; hence lies the importance of early detection of diabetic polyneuropathy. Electrophysiological studies are the most sensitive and specific methods for detection of diabetic polyneuropathy. The present study was designed to evaluate and compare nerve conduction study parameters in motor nerves in patients of diabetes mellitus and in normal healthy controls. The study included 30 healthy controls and 60 known cases of diabetes, all aged 40-60 years. Of the 60 diabetics, 30 presented with symptoms of neuropathy and 30 presented without symptoms of neuropathy. Nerve conduction studies were performed using the equipment Neuro Perfect 4channel EMG NCV EP and latencies, amplitudes and conduction velocities were evaluated. The latency, amplitude and velocity in cases were significantly different from those in controls. The mean latencies of median, ulnar, common peroneal and posterior tibial nerves in cases when compared to controls differed highly significantly. The mean amplitudes of median, ulnar and posterior tibial nerves in the cases differed statistically significantly in comparison to controls. On comparing the mean velocity of median, ulnar, common peroneal and posterior tibial nerves, the difference was statistically highly significant.
\end{abstract}

Copy Right, IJAR, 2016,. All rights reserved.

\section{Introduction:-}

One disease that has plagued man for a very long time is diabetes mellitus. It is now the third most common cause of morbidity and mortality worldwide, after cardiovascular diseases and malignancies. The International Diabetes Federation estimates that there are 285 million people with diabetes worldwide in 2010, and projects the absolute number will surpass 400 million in the coming twenty years (Textbook of diabetes, 4th edition).

Both microvascular and macrovascular complications are predominant features of diabetics at diagnosis, owing to late presentation. The most common and troublesome complication of diabetes is diabetic neuropathy, which covers a wide range of abnormalities involving both peripheral and autonomic nerve functions (Dyck P J et al, 1999). 
Distal peripheral neuropathy (DPN), also known as diabetic polyneuropathy, affects the peripheral nervous system and is by far the most common type of neuropathy seen in diabetes (Melton LJI et al, 1999).

The prevalence of diabetic polyneuropathy varies in the literature from 5 -100\% (Vinik A I et al., 2004).

The current concept of diabetic polyneuropathy is that nerve damage begins early in the course of the disease, worsening gradually over time without clinical symptoms until the condition is fairly advanced. The initial pathogenetic mechanism for developing neuropathy is metabolic which is completely reversible by good glycemic control. The later stages involve ischaemic process which is irreversible and ultimately leads to devastating complications. Hence there is a need for earlier diagnosis, evaluation, regular examinations and proper patient education (Apelquist J et al, 1999). Simple screening methods are of limited value in early neuropathy. Nerve conduction studies (NCS) are the most sensitive and specific method for detection of diabetic polyneuropathy (Perkins B A et al, 2001).

NCS help to:-

* Localize the site or level of the lesion, determining if the pathology involves the peripheral nerve, neuromuscular junction, plexus, nerve root or anterior horn cells.

* Identify the pathophysiology, in particular, distinguishing axonal loss from demyelination.

* Diagnose mononeuropathies

* Diagnose more diffuse processes (eg. generalized peripheral neuropathy due to diabetes or GBS) (Huynh W et al., 2011).

In electrodiagnostic studies, three electrodes are used : active, reference and ground. The action potential is measured between active and reference electrodes and the ground electrode serves as a zero voltage reference point. The electrodes are made up of a variety of metals and alloys such as stainless steel, platinum, silver chloride, nickel, chromium, silver and gold. A metal electrode when interacts with an electrolyte such as sweat, electrode paste or fluid, an electrochemical reaction occurs which results in an electrode polarization potential. Both surface and needle electrodes can be used. In motor nerve conduction studies, the active electrode is placed over the motor point, which is usually at the midpoint between the origin and insertion of the muscle. The reference electrode is placed on the tendon. The distance between the active and reference electrodes is standardised. Stimulators are required for nerve conduction studies. For effective nerve stimulation, stimulus duration of $50-1000 \mu$ s is required. Therefore, voltage and duration controls are provided in the equipment. The motor nerve is stimulated atleast at two points along its course. The pulse is adjusted to record a compound muscle action potential (CMAP). Supramaximal stimulation is needed. Surface electrodes are commonly used and placed in belly tendon montage. Ground electrode is placed between stimulating and recording electrodes. A biphasic action potential with initial negativity is thus recorded. The measurements for motor nerve conduction study include the onset latency, duration and amplitude of CMAP and nerve conduction velocity. The onset latency is the time in milliseconds from the stimulus to the first negative deflection of CMAP. It is a measure of conduction in the fastest conducting motor fibres. It also includes neuromuscular transmission time and the propagation time along the muscle membrane which constitute the residual latency. The amplitude correlates with the number of nerve fibres. Duration correlates with the density of small fibres. Motor nerve conduction velocity is calculated by measuring the distance in millimetre between two points of stimulation divided by the latency difference in millisecond. The nerve conduction velocity is expressed as $\mathrm{m} / \mathrm{s}$ (Mishra and Kalita, $2^{\text {nd }}$ edition).

Normal values of motor NCS (mean \pm SD) : (Kimura J, 1986; Mishra and Kalita, $2^{\text {nd }}$ edition)

\begin{tabular}{|c|c|c|c|c|c|}
\hline Nerve & Recording site & Stimulation site & Latency (ms) & $\begin{array}{l}\text { Amplitude } \\
(\mathrm{mv})\end{array}$ & $\begin{array}{c}\text { Conduction } \\
\text { velocity }(\mathrm{m} / \mathrm{s})\end{array}$ \\
\hline \multirow[t]{2}{*}{ Median } & \multirow[t]{2}{*}{ APB } & Wrist & $3.49 \pm 0.34$ & $7.0 \pm 3.0$ & \\
\hline & & Elbow & $7.39 \pm 0.69$ & $7.0 \pm 2.7$ & $57.7 \pm 4.9$ \\
\hline \multirow[t]{2}{*}{ Ulnar } & \multirow[t]{2}{*}{ ADM } & Wrist & $2.59 \pm 0.39$ & $5.7 \pm 2.0$ & \\
\hline & & Elbow & $6.1 \pm 1.69$ & $5.5 \pm 2.0$ & $58.7 \pm 5.1$ \\
\hline \multirow[t]{2}{*}{ Peroneal } & \multirow[t]{2}{*}{ EDB } & Ankle & $3.77 \pm 0.86$ & $5.1 \pm 2.3$ & \\
\hline & & Fibular head & $<5.5$ & $>2.9$ & $48.3 \pm 3.9$ \\
\hline \multirow[t]{2}{*}{ Tibial } & \multirow[t]{2}{*}{$\mathrm{AH}$} & Ankle & $<6$ & $>3.5$ & \\
\hline & & Popliteal fossa & $<6$ & $>3.5$ & $48.3 \pm 4.5$ \\
\hline
\end{tabular}


In the light of the above facts, the present study was conducted to compare the findings of nerve conduction studies of motor nerves of diabetic patients, with or without symptoms of neuropathy, with those of normal subjects.

\section{Material and Methods:-}

The present study was carried out in the Department of Physiology, in collaboration with the Department of Neurology, Assam Medical College and Hospitals, Dibrugarh after due permission from the ethics committee of Assam Medical College and Hospitals, Dibrugarh. The study was undertaken for a duration of one year. The study dealt with 90 subjects that included 30 healthy controls, 30 diabetic patients with symptoms of neuropathy and 30 diabetic patients without symptoms of neuropathy. Diagnosed cases of diabetes mellitus between the age-group of 40-60 years, of both sexes, attending the diabetes clinic in AMCH, Dibrugarh were included. Patients with history of earlier cranial nerve lesion, stroke, alcohol abuse, chronic renal failure, hereditary neuromuscular disease and those taking drugs with the potential to cause neuropathy were excluded from the study. The equipment used was Neuro Perfect 4-channel EMG NCV EP. A detailed history was taken. Patients were questioned regarding the duration of diabetes, chief complaint at presentation, present symptoms of neuropathy and the limbs involved. Prior to the test, the patient was explained that he/she would experience a 'tingling' or 'tapping' sensation. Written consent was taken from the cases as well as controls. Motor nerves included in this study were median, ulnar, common peroneal and posterior tibial nerves. The parameters tested were amplitude, latency and conduction velocity. The NCS was performed according to standard protocols and settings. Surface electrodes and surface stimulators were used. Three types of electrodes were used: active, reference and ground. The electrodes were coated with electroconductive gel and placed with adhesive tapes. The concerned nerves were tested bilaterally in all subjects. Data was analyzed using GraphPad Prism 6 for Windows version 6.05. The statistical methods used were Chi square test, Fisher's exact test and Student t-test as and where applicable. A p-value $<0.05$ was considered statistically significant, a p-value $<$ 0.001 was considered statistically highly significant, while a p-value $>0.05$ was considered statistically nonsignificant.

\section{Result:-}

In the present study, out of the 60 diabetic cases, 30 were cases with symptoms of neuropathy and 30 were cases without symptoms of neuropathy. Among the 30 cases with symptoms of neuropathy, 15 (50\%) were males and 15 (50\%) were females. Among the 30 cases without symptoms of neuropathy, $15(50 \%)$ were males and 15 (50\%) were females. Among the 30 healthy controls also 15 (50\%) were males and $15(50 \%)$ were females. Table 1 shows the sex distribution of cases and controls.

Table 1:- Table showing sex distribution of diabetes cases and controls.

\begin{tabular}{|c|c|c|c|c|c|c|}
\hline \multirow{2}{*}{ Sex } & \multicolumn{2}{|c|}{$\begin{array}{c}\text { Diabetes cases with } \\
\text { symptoms of } \\
\text { neuropathy }\end{array}$} & $\begin{array}{c}\text { Diabetes cases } \\
\text { without symptoms of } \\
\text { neuropathy }\end{array}$ & \multicolumn{2}{|c|}{ Controls } \\
\cline { 2 - 7 } & No. & $\%$ & No. & $\%$ & No. & $\%$ \\
\hline Male & 15 & 50 & 15 & 50 & 15 & 50 \\
\hline Female & 15 & 50 & 15 & 50 & 15 & 50 \\
\hline Total & 30 & 100 & 30 & 100 & 30 & 100 \\
\hline
\end{tabular}

The mean age of the diabetes cases was $49.92 \pm 6.75$ years while the mean age of the healthy controls was $47.30 \pm$ 5.40 years. There was no significant difference between the mean ages of the cases and controls as shown in Table 2.

Table 2:- Table showing age distribution of cases and controls.

\begin{tabular}{|c|c|c|c|}
\hline \multirow{2}{*}{ Mean age } & Case & Control & $\mathrm{p}$-value \\
\cline { 2 - 4 } & $49.92 \pm 6.75$ & $47.30 \pm 5.40$ & $\mathrm{p}=0.068$ \\
\hline
\end{tabular}


Figure 1 shows that of the 60 cases of diabetes that included diabetics with symptoms of neuropathy as well as diabetics without symptoms of neuropathy, all 60 (100\%) showed abnormal changes in nerve conduction studies.

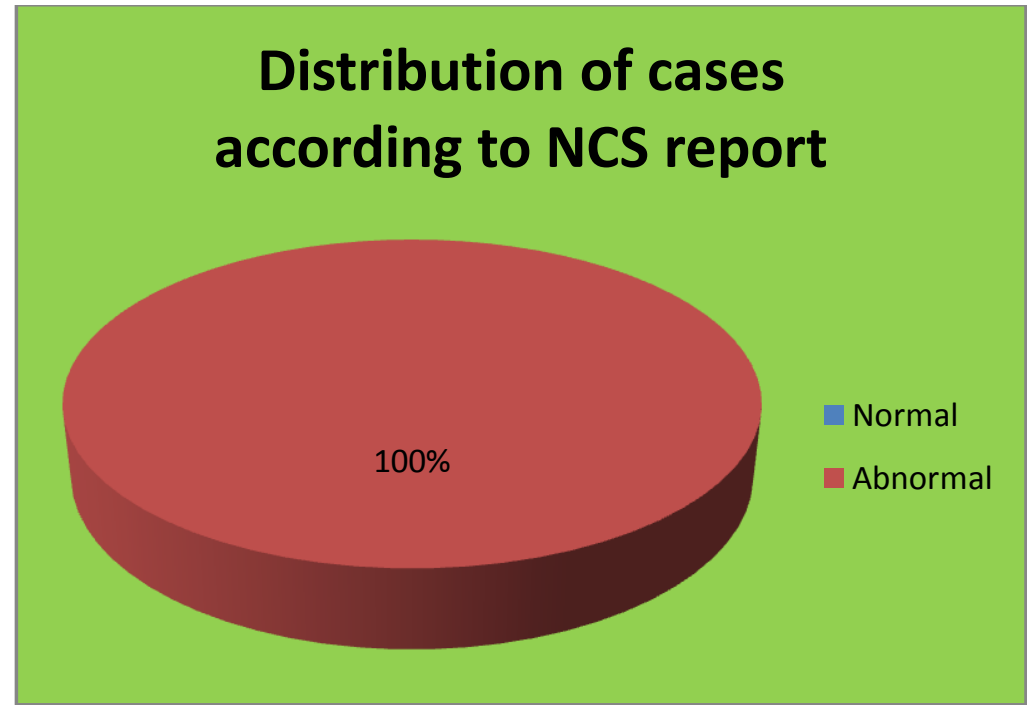

Fig 1:- Figure showing the distribution of cases according to nerve conduction study report.

Among the 30 cases presenting with symptoms of neuropathy, all 30 (100\%) showed motor nerve involvement while $27(90 \%)$ showed sensory nerve involvement. Of the 30 cases presenting without symptoms of neuropathy, all $30(100 \%)$ showed motor nerve involvement while $27(90 \%)$ showed sensory nerve involvement as shown in figure 2. The difference between the two groups was not significant.

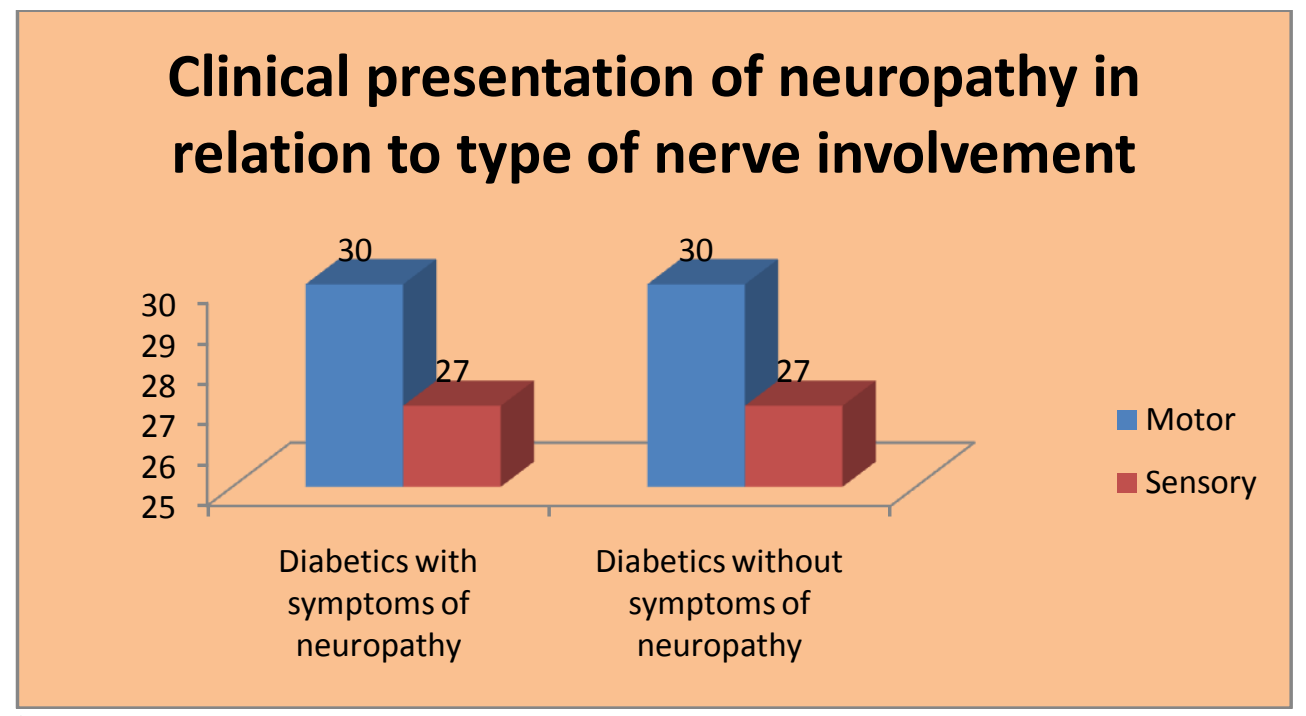

Fig 2:- Figure showing type of nerve involvement in relation to clinical presentation of neuropathy . 
Figure 3 shows the distribution of cases according to the involvement of motor nerves. Ulnar motor nerve was found to be affected in $59(98.33 \%)$ cases, median motor nerve was affected in $55(91.67 \%)$ cases, common peroneal nerve was affected in $51(85 \%)$ cases, posterior tibial nerve was affected in $50(83.33 \%)$.

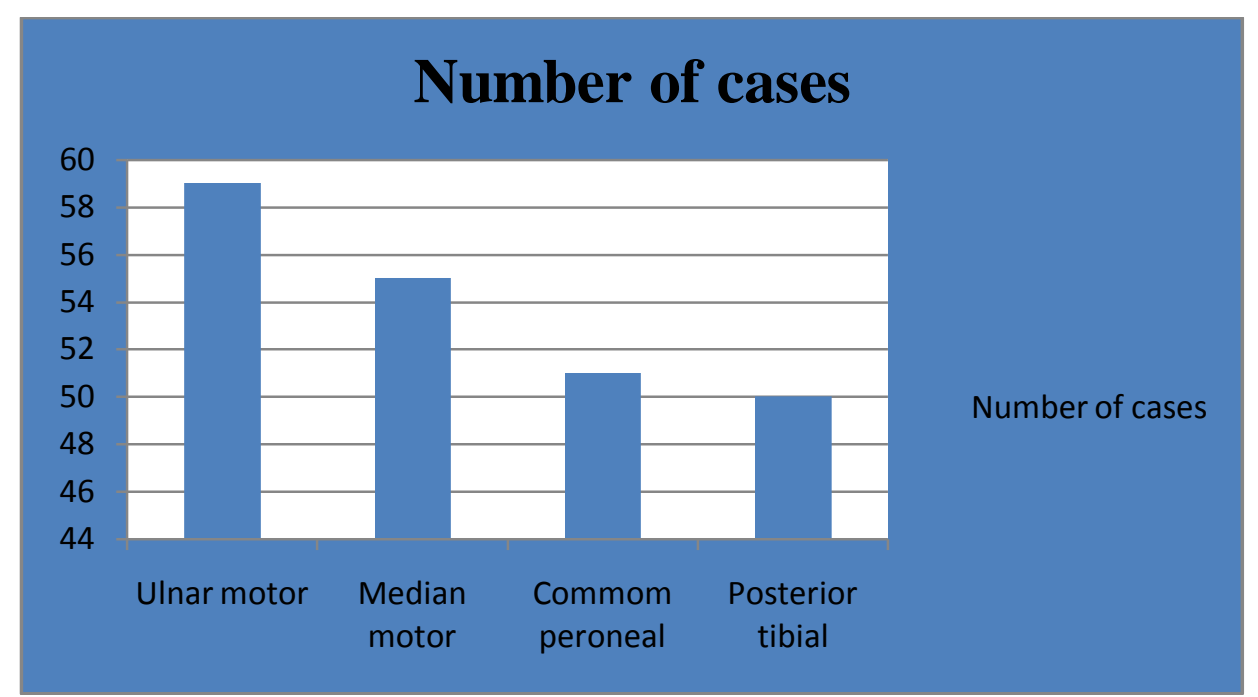

Fig 3: Figure showing the distribution of cases according to motor nerve involvement.

Figure 4 shows that the mean latency, amplitude and velocity of motor nerves in cases were respectively $4.79 \pm 2.36$ $\mathrm{ms}, 5.15 \pm 3.28 \mathrm{mv}$ and $38.27 \pm 14.73 \mathrm{~m} / \mathrm{s}$. While in the controls the same were $3.74 \pm 1.08 \mathrm{~ms}, 7.66 \pm 2.88 \mathrm{mv}$ and $53.86 \pm 5.47 \mathrm{~m} / \mathrm{s}$ respectively. The parameters differed highly significantly between the two groups, with a p-value of $<0.0001$.

\section{Nerve conduction parameters of motor nerves in cases and controls}

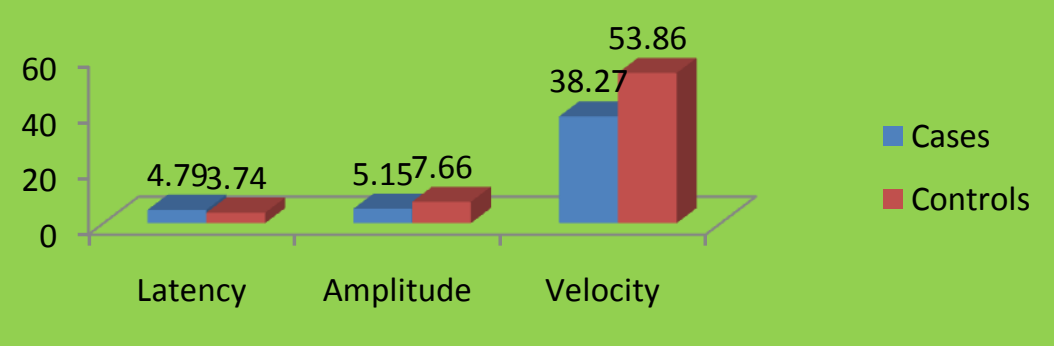

Fig 4: Figure showing comparison of nerve conduction parameters of motor nerves in cases and controls. 
Figure 5 shows that the mean latency of median, ulnar, common peroneal and posterior tibial nerves in cases were respectively $4.87 \pm 1.33 \mathrm{~ms}, 3.89 \pm 1.57 \mathrm{~ms}, 4.98 \pm 3.03 \mathrm{~ms}$ and $5.46 \pm 2.80 \mathrm{~ms}$. While the same in the controls were respectively $3.38 \pm 0.50 \mathrm{~ms}, 2.58 \pm 0.35 \mathrm{~ms}, 4.17 \pm 0.79 \mathrm{~ms}$ and $4.86 \pm 0.91 \mathrm{~ms}$. The mean latencies in cases when compared to controls differed highly significantly, with a p-value of $<0.001$.

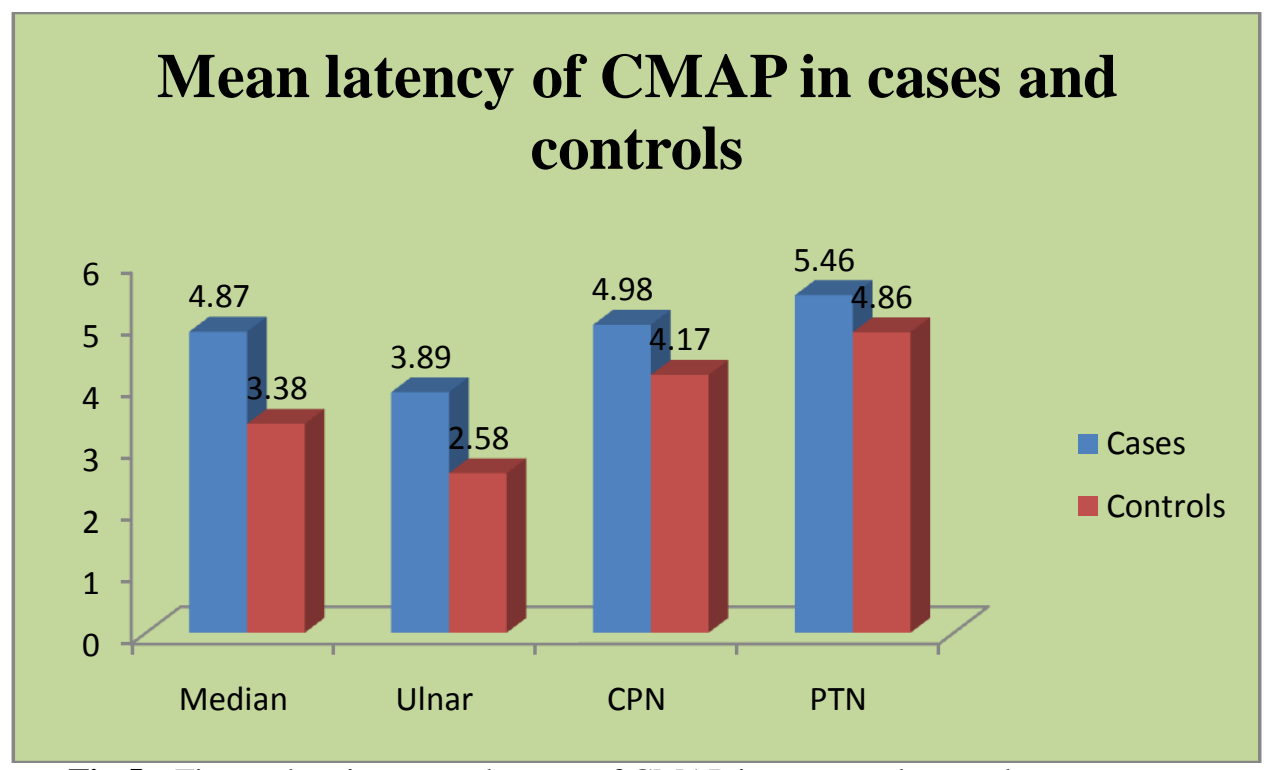

Fig 5:- Figure showing mean latency of CMAP in cases and controls.

The mean amplitude of median, ulnar, common peroneal and posterior tibial nerves were $6.88 \pm 2.93 \mathrm{mv}, 6.37 \pm$ $2.42 \mathrm{mv}, 2.87 \pm 2.52 \mathrm{mv}$ and $4.46 \pm 3.55 \mathrm{mv}$ respectively. While the same among the controls were respectively $10.49 \pm 2.06 \mathrm{mv}, 8.23 \pm 1.58 \mathrm{mv}, 4.34 \pm 1.12 \mathrm{mv}$ and $7.56 \pm 2.45 \mathrm{mv}$. The mean amplitudes of median, ulnar and posterior tibial in the cases in comparison to the controls differed statistically highly significantly, with a p-value of $<0.001$, as is shown in Figure 6.

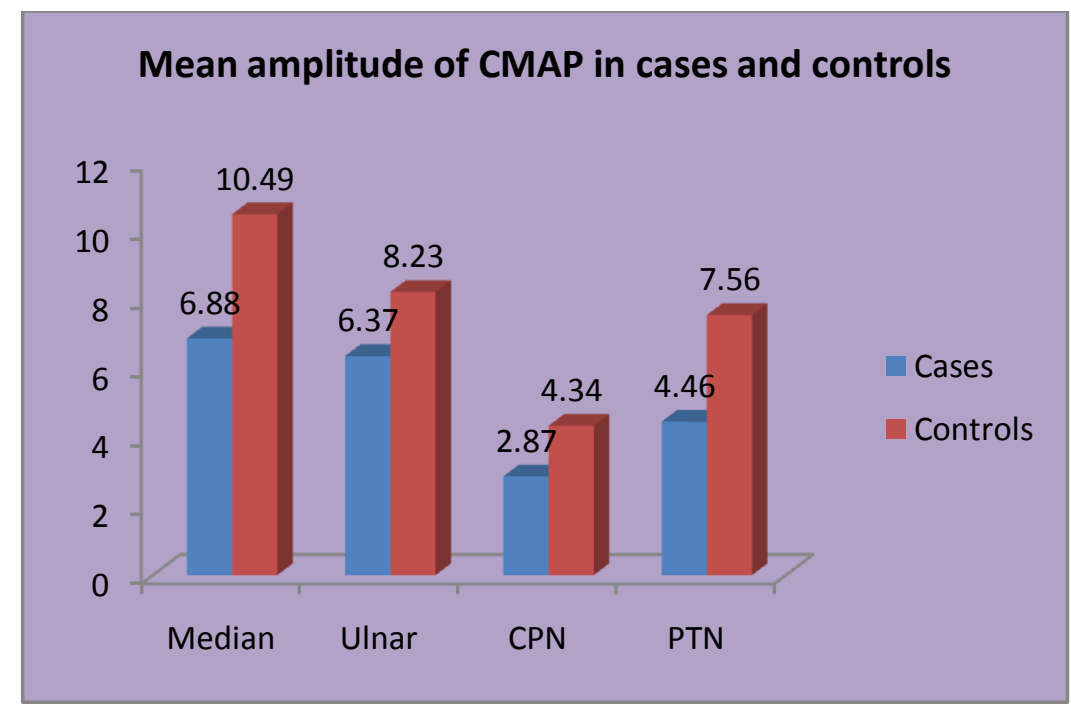

Fig 6:- Figure showing mean amplitude of CMAP in cases and controls 
Figure 7 shows that among the cases, the mean velocity of median, ulnar, common peroneal and posterior tibial nerves were respectively $42.30 \pm 10.90 \mathrm{~m} / \mathrm{s}, 43.24 \pm 11.62 \mathrm{~m} / \mathrm{s}, 32.62 \pm 17.54 \mathrm{~m} / \mathrm{s}$ and $34.91 \pm 15.22 \mathrm{~m} / \mathrm{s}$. While among the controls the same were $56.41 \pm 5.27 \mathrm{~m} / \mathrm{s}, 56.94 \pm 4.51 \mathrm{~m} / \mathrm{s}, 51.44 \pm 4.76 \mathrm{~m} / \mathrm{s}$ and $50.68 \pm 4.34 \mathrm{~m} / \mathrm{s}$. On comparing the two groups, the difference was statistically highly significant.

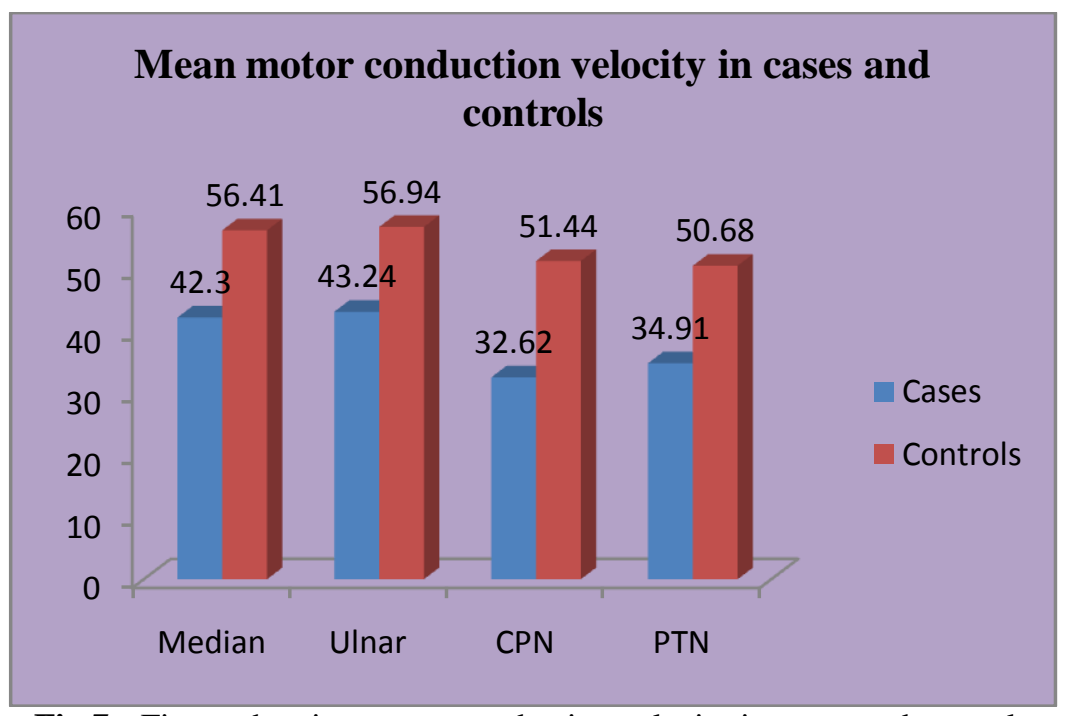

Discussion:-

Fig 7:- Figure showing motor conduction velocity in cases and controls

In our study, diabetics with symptoms of neuropathy as well as diabetics without symptoms of neuropathy showed abnormal NCS findings, although the difference between the two groups was not statistically significant. The finding is comparable to findings of the studies by Ambreen Asad et al. in 2009. 60 diabetics were evaluated, 30 with symptoms of neuropathy and 30 without symptoms of neuropathy. The results of the study showed that both clinical assessment and NCS are valuable in detecting cases of peripheral neuropathy. However, NCS is a more powerful tool for detection of neuropathy as it is helpful for detecting subclinical neuropathies as well. Similar finding was also found by Liu M S et al. in their study conducted in China in 2005. In this study 700 diabetic subjects were evaluated and it was found that subclinical diabetic peripheral neuropathy could be detected by electrophysiological methods. In 2001, Niazi et al. carried out a study in 41 diabetics in Pakistan and it was reported that NCS could diagnose diabetic polyneuropathy much before clinical symptoms and signs were manifested, which is comparable to our study. The findings of the present study are consistent with the findings of Chopra et al. who reported in 1969 that nerve conduction abnormalities are present in more than 80\% of asymptomatic newly diagnosed diabetics.

In the present study, among the 60 diabetic subjects, motor nerve involvement was found in all 60 subjects while sensory nerve involvement was found in 54 subjects. Among the 30 cases presenting with symptoms of neuropathy, $30(100 \%)$ showed motor nerve involvement while $27(90 \%)$ showed sensory nerve involvement. Of the 30 cases presenting without symptoms of neuropathy, 30 (100\%) showed motor nerve involvement while 27 (90\%) showed sensory nerve involvement. The difference between the two groups was not significant. This finding of predominant motor involvement in diabetes is in stark contrast to the otherwise accepted view that sensory fibres are more commonly affected in diabetes. This disparity could well be due to the fact that sural sensory nerve, which is usually the most commonly affected nerve, could not be included in our study owing to some technical difficulties in our facility. This is comparable to the finding of predominant motor abnormality in newly diagnosed diabetics by Bhowmik in 1999. The present study is also consistent with the study by Biswas in 2003 who reported deterioration of motor nerve function without sensory dysfunction in type 2 diabetics with short duration of diabetes. A study by Sultana S et al. in 2009 also revealed significant motor nerve abnormalities in diabetics with shorter as well as longer duration of diabetes. This finding of predominant motor involvement could be considered to be a characterictic of the local population. It was also put forward that there might be a genetic basis for motor involvement in the subjects under study. 
In the present study, the nerve most commonly affected is ulnar motor (98.33\%), followed by median motor (91.67\%), common peroneal (85\%), posterior tibial (83.33\%), ulnar sensory (78.33\%) and median sensory (78.33\%). Studies by Al-Muhammadi et al. and Karsidag et al. showed that the most common nerve involved by diabetic polyneuropathy is sural nerve followed by median sensory nerve, common peroneal nerve, posterior tibial nerve, ulnar sensory nerve, median and ulnar motor nerves. A study by Hendriksen et al. in 1993 revealed that nerve conduction abnormalities were most pronounced in motor nerves of the leg (Tibial), followed, in order of severity, by sensory nerves of the leg (sural), sensory nerves of the arm (ulnar ) and motor nerves of the arm (ulnar ).

In our study, the mean latency of motor nerves was significantly increased in cases when compared to that of controls. The mean amplitude and mean velocity of motor nerves were significantly reduced in cases as compared to controls. On comparing the mean latencies of median, ulnar, common peroneal and posterior tibial nerves between cases and controls it was seen that latencies were significantly increased in cases. The mean amplitudes of median, ulnar, common peroneal and posterior tibial nerves in the cases were reduced in comparison to the controls. The difference was statistically significant in median,ulnar and posterior tibial nerves. Statistically highly significant difference was found on comparing the mean velocities of median, ulnar, common peroneal and posterior tibial nerves of cases and controls. Sultana S et al. (2009) carried out a study on 69 diabetics that included both males and females. Nerve conduction parameters of ulnar and common peroneal nerves were measured. Ulnar amplitude, peroneal amplitude and peroneal velocity were significantly reduced in diabetics in comparison to controls. Increase in ulnar and peroneal latency were observed in diabetics with long duration of diabetes, though the difference was not significant in comparison to non-diabetics. Fraser et al. (1977) investigated 10 newly diagnosed diabetics who were on insulin and oral hypoglycemics. Nerve conduction velocity and latency were estimated in common peroneal, motor median and motor ulnar nerves. The mean conduction velocity of common peroneal nerve was delayed at the time of diagnosis. Ulnar motor conduction velocity and latency were within normal range for all subjects. Motor conduction velocity and latency of median nerve also were within normal range for all subjects. Shekharappa K R et al. studied 90 diabetics aged between 40-60 years in 2011. Latency, amplitude and conduction velocity were assessed for ulnar motor nerve. Significant reduction in conduction velocity and amplitude was observed in cases as compared to the controls. Significant increase in latency was seen in cases when compared with controls. These findings are comparable to the present study.

\section{Conclusion:-}

The results demonstrated $100 \%$ abnormal NCS, with $100 \%$ motor involvement and $90 \%$ sensory involvement in diabetics with symptoms of neuropathy as well as diabetics without symptoms of neuropathy. The most common nerve to be affected was ulnar motor nerve, followed by median motor, posterior tibial, common peroneal, ulnar sensory and median sensory. NCS of motor nerves showed significant increase in mean latency and significant decrease in mean amplitude as well as mean velocity of conduction in cases as compared to controls. 


\section{References:-}

1. Ambreen Asad, Amina Nadeem, Muhammed Amjad Hameed, Umar Ali Khan, Mujeeb-ur-Rahman Abid Butt, Nadeem Ahmed. Comparison of nerve conduction studies with diabetic neuropathy symptom score and diabetic neuropathy examination score in type 2 diabetics for detection of sensory motor polyneuropathy. JPMA 59:594; 2009.

2. Apelquist J, Balcker K, Van Houtum WQH, Nabuurs Fransen MH. Schaper NC: International consensus on the diabetic foot. In the International working groups on the diabetic foot. Amsterdam, Netherlands, John Wiley and Sons, 1999, :p 67.

3. Bhowmik NB. Pathophysiology of early neuropathic changes in young diabetic subjects (Thesis). Dhaka: BSMMU; 1999.

4. Biswas SK. Role of C-peptide and insulin secretory defect and resistance in the pathogenesis of nerve conduction abnormalities in diabetic neuropathy. Dhaka: BSMMU; 2003.

5. Chopra and Hurwitz. Comparative study of peripheral nerve conduction in diabetes and non-diabetic chronic occlusive peripheral vascular disease. Brain 1969; 92: 83-96.

6. Dyck PJ, Thomas PK. Diabetic Neuropathy, Second Edition,Philadelphia, W. B. Saunders, 1999.

7. Fraser DM, Campbell I W, Ewing DJ, Murray A, Neilson JMM, Clarke BF. Peripheral and Autonomic Nerve Function in Newly Diagnosed Diabetes Mellitus. DIABETES 26:546-50, June, 1977.

8. Hendriksen $\mathrm{P} \mathrm{H}$, Oey $\mathrm{P}$ L, Wieneke $\mathrm{G} \mathrm{H}$, Bravenboer B, van Huffelen A C. Subclinical diabetic polyneuropathy: early detection of involvement of different nerve fibre types. Journal of Neurology, Neurosurgery, and Psychiatry 1993;56:509-514.

9. Holt RIG, Cockram C, Flyvbjerg A, Goldstein BJ, 2010. Textbook of diabetes. $4^{\text {th }}$ ed. Singapore: WileyBlackwell.

10. Huynh W. Nerve conduction studies. Australian Family Physician.2011; 40(9): 693

11. Karsidaga S.; Moralıa S.; Sargınb M.; Salmanc S.; Karsidagc K. and Usa O. (2005). The electrophysiological findings of subclinical neuropathy in patients with recently diagnosed type 1 diabetes mellitus. Diabetes Research and Clinical Practice 67:211-219.

12. Kimura J. Electrodiagnosis in diseases of nerve and muscle. Principles and Practice. FA Davis, Philadelphia, 1986.

13. Liu MS, Hu BL, Cui LY, Tang XF, Du H, Li BH. Clinical andneurophysiological features of 700 patients with diabetic peripheralneuropathy. Zhonghua Nei Ke Za Zhi 2005; 44:173-6.

14. Melton LJI, Dyck PJ: Epidemiology: In Diabetic Neuropathy. 2nd edition. Philadelphia: W.B. Saunders; 1999.

15. Mishra U K, Kalita J. Clinical neurophysiology, Second edition.2006.

16. Muhammad O.Al-Muhammadi, Fadhel Al-Hameery,Zahid M Ali Mohyee Al-Deen. Some physiological and clinical changes in patients with diabetic peripheral neuropathy. Medical Journal of Babylon; Vol 8-No. 4. 2011.

17. Niazi PHK, Ahmad K, Hussain A, Butt AW, Alam A. Electrodiagnostic Evaluation of Diabetic Polyneuropathy. Pak Armed Forces Med J 2001; 51: 75-7.

18. Perkins BA, Olaleye D, Zinman B, Bril V. Simple screening tests for peripheral neuropathy in the diabetes clinic. Diabetes Care. 2001; 24(2): 250-6.

19. Shekharappa K R, Srinivas A K, Vedavathi K J, Venkatesh G.A Study on the Utility of Nerve Conduction Studies in Type 2 Diabetes Mellitus. Journal of Clinical and Diagnostic Research. 2011 June, Vol-5(3): 529531.

20. Sultana S, Begum N, Ali L, Hossain MM, Bhowmik NB, Parveen Z. Electrophysiological changes of motor nerves in patients with type 2 diabetes mellitus. JAFMC Bangladesh. Vol 5, No. 2 (December), 2009.

21. Vinik AI, Mehrabyan A. Diabetic neuropathies. Med Clin North Am 2004; 88: 947-99, xi. 